\title{
A New Coordinated Fuzzy-PID Controller for Power System Considering Electric Vehicles
}

\section{G. Magdy ${ }^{1,2 *}$, G. Shabib'2, Adel A. Elbaset ${ }^{3}$, Thongchart Kerdphol', Yaser Qudaih1, Yasunori Mitani ${ }^{1}$}

\author{
${ }^{1}$ Department of Electrical and Electronics Engineering, Kyushu Institute of Technology, Tobata-Ku, Kitakyushu-Shi, Fukuoka, \\ Japan \\ ${ }^{2}$ Department of Electrical Engineering, Faculty of Energy Engineering, Aswan University, Aswan, Egypt \\ ${ }^{3}$ Department of Electrical Engineering, Faculty of Engineering, Minia University, Minia, Egypt \\ Email: ${ }^{\star}$ gabermagdy100@gmail.com
}

How to cite this paper: Magdy, G., Shabib, G., Elbaset, A.A., Kerdphol, T., Qudaih, Y. and Mitani, Y. (2017) A New Coordinated Fuzzy-PID Controller for Power System Considering Electric Vehicles. Energy and Power Engineering, 9, 425-435.

https://doi.org/10.4236/epe.2017.94B048

Received: February 25, 2017

Accepted: March 30, 2017

Published: April 6, 2017

\begin{abstract}
With penetration growing of renewable energy sources which integrated into power system have caused problems on grid stability. Electric Vehicles (EV) are one of the renewable energy sources that can bring significant impacts to power system during their charging and discharging operations. This article established a model of single machine infinite bus (SMIB) power system considering EV as a case study of load disturbance for power system oscillation. The objective of this research is to enhance stability and overcome the drawbacks of traditional control algorithms such as power system stabilizer (PSS), PID controller and fuzzy logic controller (FLC). The implementation's effect of FLC parallel with PID controller (Fuzzy-PID) has been shown in this paper. The speed deviation $(\Delta \omega)$ and electrical power $\left(P_{e}\right)$ are the important factors to be taken into consideration without EV (only change in mechanical torque), EV with change in the mechanical torque and sudden plug-in EV. The obtained result by nonlinear simulation using Matlab/Simulink of a SMIB power system with EV has shown the effectiveness of using (Fuzzy-PID) against all disturbances.
\end{abstract}

\section{Keywords}

Power Systems, Electric Vehicles (EV), Power System Stabilizer (PSS), Fuzzy Logic Controller (FLC), PID Controller, (Fuzzy-PID)

\section{Introduction}

Power system operation is characterized by the random variation of the load condition, continuous change in generation schedule and network interconnec- 
tion. Moreover, Power systems have usually more disturbances such as actions of different controllers, switching of lines or increasing loads in the system [1]. Electric Vehicles (EVs) have electric motor instead of engine which gained much concern as the next generation vehicles. Vehicle-to-Grid has two operating modes, a charging operation of EV absorbs power from the grid which caused frequency regulation down but discharging process power flow back to grid and caused frequency regulation up. Then, charging operation of EV uses as a load disturbance on power system [2] [3]. Such disturbances will lead to bringing low frequency oscillation in power system, which should be consequently endangering the overall stability of the system [4]. The stability of power systems is one of the most important subject which has challenged electrical engineering, therefore it is considered the first recognize as an important problem in power system operation since the 1920s [5].

In the late 1950's most of electric power systems used Automatic Voltage Regulators (AVR) for damping the power system oscillations and maintain the overall stability of the power system [4] [6]. Nowadays convention Power System Stabilizer (CPSS) is one of the most important controllers in modern electric power systems for enhancing system stability and damping the low frequency oscillations. Demello and Concordia [7] were the first to utilize the principle of phase compensation in the frequency domain to make a thorough analysis of a lead-lag compensator to give a supplemental signal in the machine excitation system. The conventional power system stabilizer (CPSS) mostly used to obtain damping to the system using speed deviation $(\Delta \omega)$ [8] [10].

In a previous work, a conventional controller such as power system stabilizer (PSS) [11], different structures of proportional-integral-derivative controller (PID) and fuzzy logic controller [12] [13] and [14] have been employed for improving the stability of a SMIB. To further enhance stability and overcome the drawbacks of convention controllers. However, considering electric vehicles $(\mathrm{EV})$ as a case study of load disturbance beside the change in mechanical torque for power system oscillation. A coordinated Fuzzy-PID controller as power system stabilizer have been used.

Recently, fuzzy logic controller (FLC) showed up as robust tool in control of complex power system. However, it has more merits than other controllers such as simplicity, low cost and its robustness and effectiveness [15]. In this paper, our contribution has been developed of a new coordinated Fuzzy-PID controller for a SMIB power system with EV as load disturbance beside the change in mechanical torque. To show the robustness and effectiveness of this coordinate under all disturbance cases than other convention controllers for all study cases.

This paper is organized as follows. In Section (2) presents the system configuration that consists of two subsections, which are driving the power system considering EV model and explains the conventional controller models (PSS and PID). Design of fuzzy-PID controller is considered in Section (3). Simulation results and analysis are presented in Section (4). Finally, the conclusion is given in Section (5). 


\section{System Configuration}

\subsection{The Power System Model}

Figure 1 show the studied system which is a Single Machine Infinite Bus (SMIB) (Kundur 1993) [4]. The model used for representing the synchronous generator connected through transmission line to a very large power network approximated by an infinite bus. The synchronous generator is driven by a turbine with a governor and excited by an external excitation system [13]. However, the plug-in EV has been considered as a load disturbance for power system oscillation and modeled as a first order system as shown in Figure 2 [16]. The Plug-in EV power control against deviation of frequency is shown in Figure 3 [2] [3], which V1G is the one-way charging power control from grid to vehicles.

Parameters $K_{1}, K_{2}, \cdots, K_{6}$ are the constant of linearized model of synchronous machine. From the blocks diagram shown in Figure 1 and Figure 2 the following fifth order linearized single machine infinite bus system considering EV which can be given in state space form as follows:

$$
\begin{aligned}
& \vec{X}=A X+B U \\
& Y=C X+D U
\end{aligned}
$$

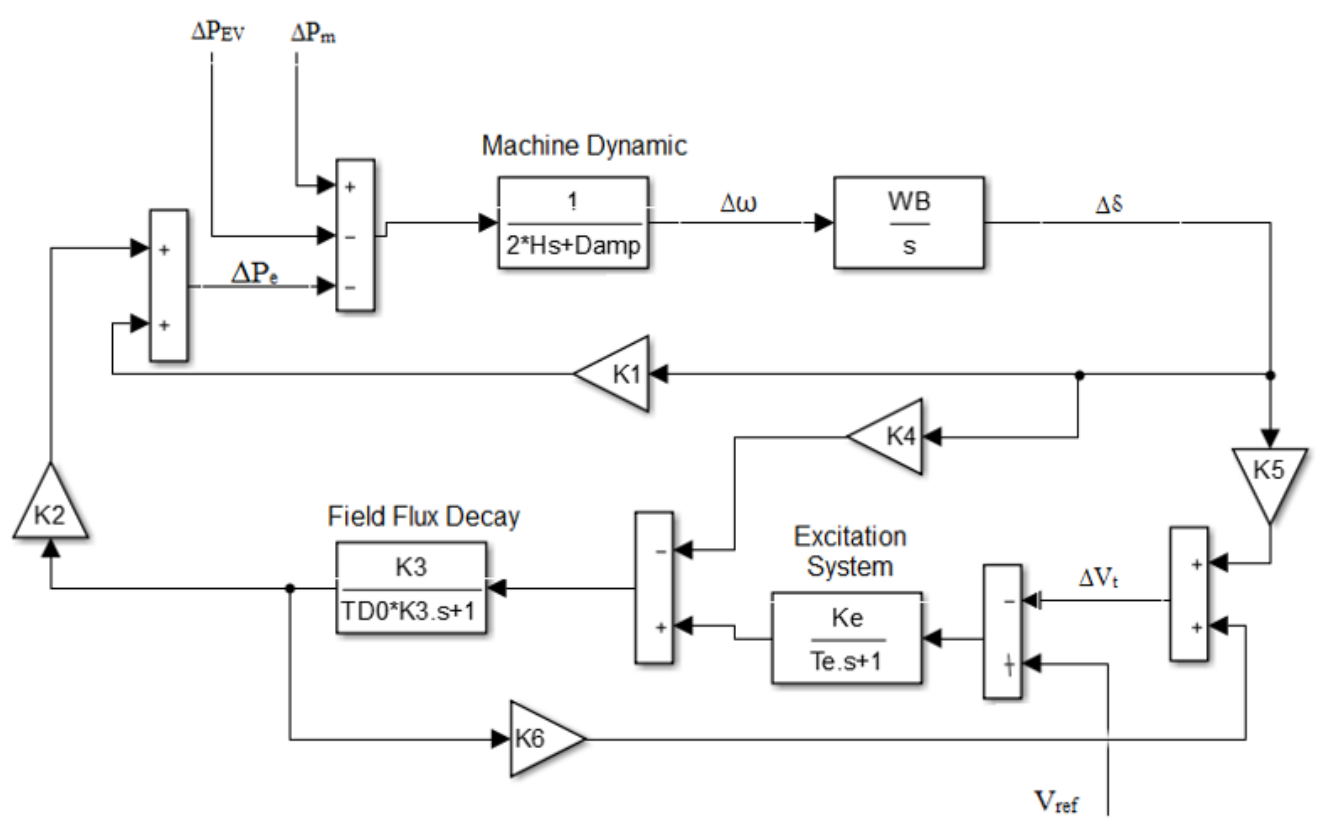

Figure 1. Block diagram of SMIB.

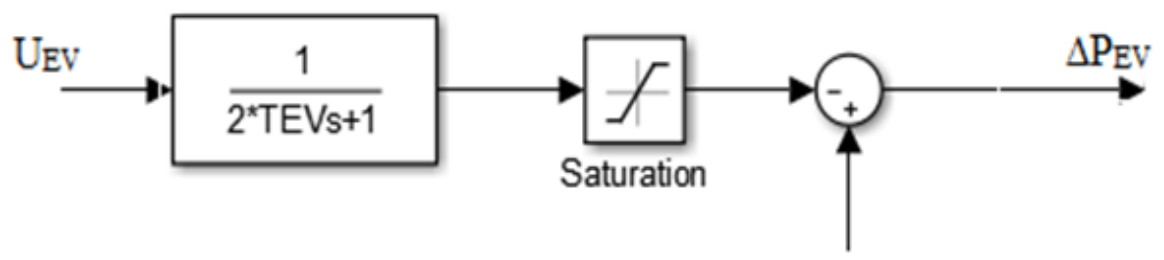

PEV-rated

Figure 2. EV model. 


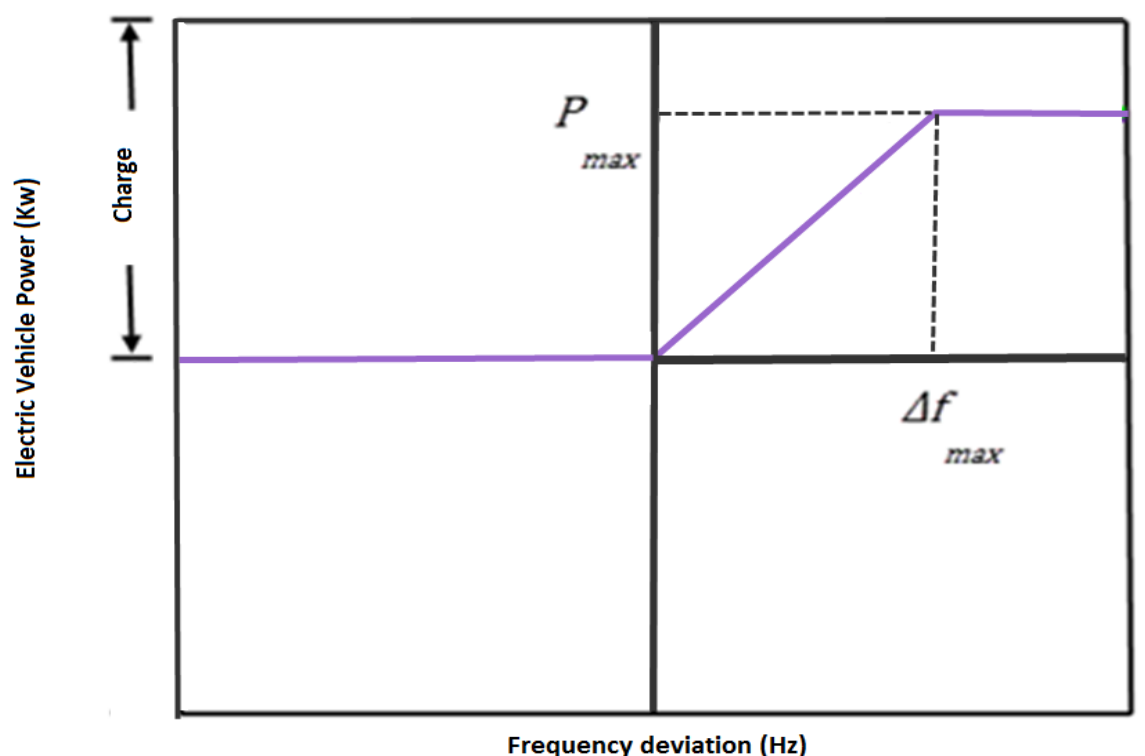

Figure 3. PEV power control against frequency deviation.

$$
\begin{gathered}
A=\left[\begin{array}{ccccc}
-\frac{D a m p}{2 H} & -\frac{K_{1}}{2 H} & -\frac{K_{2}}{2 H} & 0 & \frac{-1}{2 H} \\
\omega_{B} & 0 & 0 & 0 & 0 \\
0 & -\frac{K_{4}}{T_{d o}^{\prime}} & -\frac{1}{K_{3} T_{d o}^{\prime}} & -\frac{1}{T_{d o}^{\prime}} & 0 \\
0 & -\frac{K_{e} K_{5}}{T_{e}} & -\frac{K_{6} K_{e}}{T_{e}} & -\frac{1}{T_{E}} & 0 \\
0 & 0 & 0 & 0 & -\frac{1}{2 T_{E V}}
\end{array}\right], B=\left[\begin{array}{ccc}
\frac{1}{2 H} & 0 & 0 \\
0 & 0 & 0 \\
0 & 0 & 0 \\
0 & \frac{K e}{T e} & 0 \\
0 & 0 & \frac{1}{2 T E V}
\end{array}\right] \\
X=\frac{d}{d t}\left[\begin{array}{c}
\Delta \omega \\
\Delta \delta \\
\Delta \psi_{f d} \\
\Delta E_{f d} \\
\Delta P_{E V}
\end{array}\right], U=\left[\begin{array}{c}
\Delta P_{m} \\
\Delta V_{r e f} \\
U_{E V}
\end{array}\right], C=\left[\begin{array}{llll}
1 & 0 & 0 & 0
\end{array}\right], D=\left[\begin{array}{lll}
0 & 0 & 0
\end{array}\right]
\end{gathered}
$$

The speed deviation $\Delta \omega$ is assumed to be measured as the output of the system. The constants of the generation system and EV which are connected to power system used for study are given in Appendix I [4].

The damping coefficient (Damp) is included in the swing equation. The eigenvalues of the matrix A should lie in LHP in the S-plane for the system to be stable. It is to be noted that the elements of matrix A are depended on the operating condition. The values of $K_{1}, K_{2}, \cdots, K_{6}$ in the matrix A are to be calculated according to the operating conditions of the generation system and connected power System [4]. Details of these constants are given in Appendix II.

\subsection{Conventional Controller Models}

\subsubsection{Power System Stabilizer Model (PSS)}

PSS is widely used in the power system to improve the damping oscillations of the power system; sometime it is called the damping controller. The PSS is con- 
sidered as comprising two cascade connected blocks, commonly lead-lag structure [1]. The PSS structure is illustrated in Figure 4.

The gain determine the amount of damping and it is chosen by trial and error method and The washout stage is used to prevent a steady-state voltage shift, then the washout time constant $T_{I}$ is chosen in between 0 to $20 \mathrm{sec}$; $T_{2}, T_{3}$, $T_{4}$ and $T_{5}$ are time constants of the lead-lag type [10].

\subsubsection{PID Controller}

The proportional integral and derivative (PID) controller is a one of the earliest industrial controllers. It has many advantages: Its cost is economic, simple easy to be tuned and robust [17] [18] [19]. The practical PID structure is illustrated in Figure 5.

In the parallel form of the PID controller, there are three simple gains $K_{P}$, $K_{I}$ and $K_{D}$ are used in the decoupled branches of the PID controller which tuned by using PID tuner in Simulink model. The term $(1 /(\tau s+1))$ acts as an effective low-pass filter on the $\mathrm{D}$ regulator to attenuate noise in the derivative block [18].

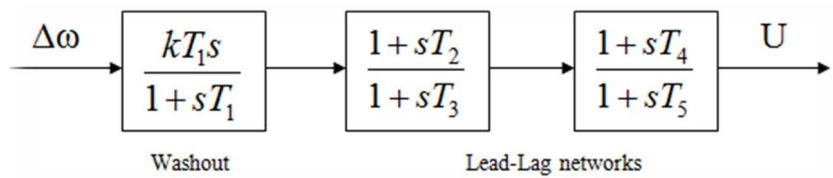

Figure 4. Structure of PSS.

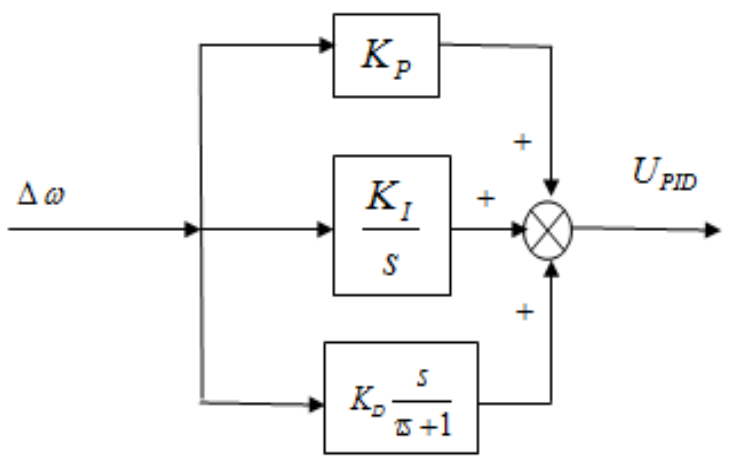

Figure 5. Structure of PID.

\section{Design of Fuzzy-PID Controller}

The proposed coordinated of Fuzzy-PID controller block diagram is given in Figure 6. Speed deviation and acceleration have been selected as controller inputs, and the output of the coordination (Fuzzy-PID) is injected into voltage summing point.

All inputs and output variable of (FLC) are seven linguistic fuzzy which are defined as NB, NM, NS, ZO, PS, PM and PB means Negative Big, Negative Medium, Negative Small, Zero, Positive Small, Positive Medium and Positive Big [20]. The performance of FLC depends on the membership fuctions which are triangular is this paper. 


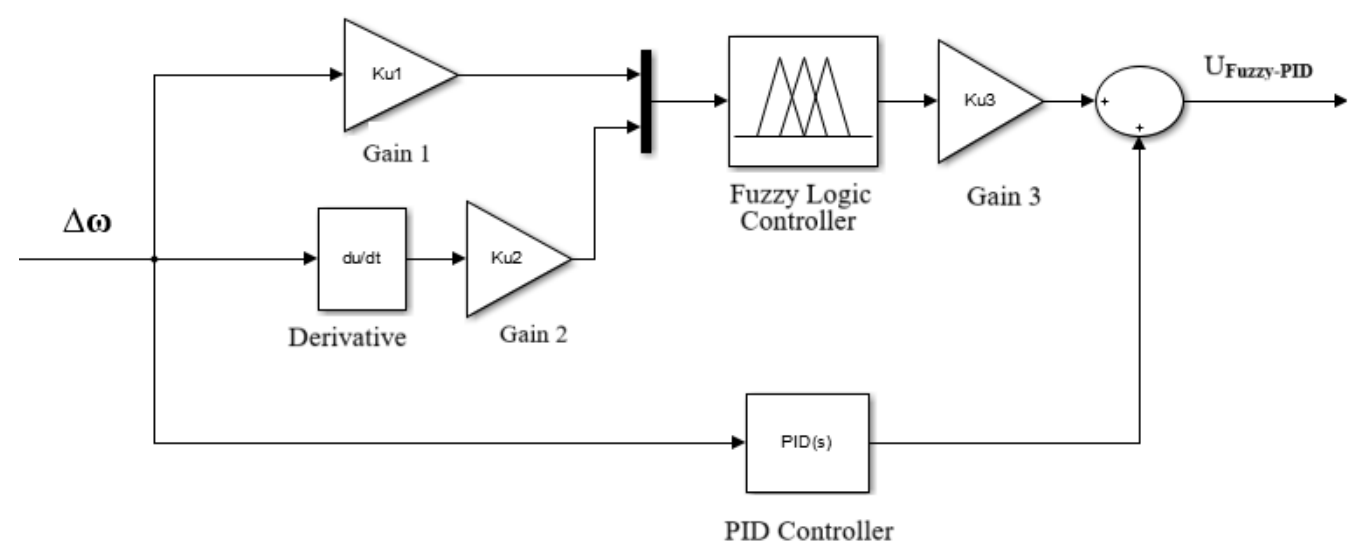

Figure 6. Structure of Fuzzy-PID.

Inputs and output values which are speed deviation, acceleration inputs and reference voltage output lies between [-1:1] and we adjust inputs factors $\mathrm{Ku} 1$, $\mathrm{Ku} 2$ to normalize inputs and then we change $\mathrm{Ku} 3$ to obtain optimal result [20].

Designing the coordinated of (Fuzzy-PID) depends on designing FLC and PID, tuning PID controller by using PID tuner in Matlab/Simulink model. However, FLC needs the definition of control rules, we have used the algorithm [20] developed to generate them. The speed deviation and acceleration results in 49 rules for this model, these rules shows in Table 1 .

Table 1. Fuzzy rule bases.

\begin{tabular}{|c|c|c|c|c|c|c|c|c|}
\hline \multicolumn{2}{|c|}{$\mathrm{U}_{\text {Fuzzy }}$} & \multicolumn{7}{|c|}{$\frac{d}{d t}(\Delta \omega)$} \\
\hline & & NB & NM & NS & $\mathrm{ZO}$ & PS & PM & PB \\
\hline \multirow{7}{*}{$\Delta \omega$} & NB & NB & NB & $\mathrm{NB}$ & $\mathrm{NB}$ & NM & NS & $\mathrm{ZO}$ \\
\hline & NM & NB & NM & NM & NM & NS & $\mathrm{ZO}$ & PS \\
\hline & NS & NB & NM & NS & NS & $\mathrm{ZO}$ & PS & $\mathrm{PM}$ \\
\hline & $\mathrm{ZO}$ & NB & NM & NS & $\mathrm{ZO}$ & PS & PM & PB \\
\hline & PS & NM & NS & $\mathrm{ZO}$ & PS & PS & $\mathrm{PM}$ & PB \\
\hline & $\mathrm{PM}$ & NS & $\mathrm{ZO}$ & PS & $\mathrm{PM}$ & $\mathrm{PM}$ & $\mathrm{PM}$ & PB \\
\hline & $\mathrm{PB}$ & $\mathrm{ZO}$ & PS & PS & PB & $\mathrm{PB}$ & $\mathrm{PB}$ & PB \\
\hline
\end{tabular}

\section{Simulation Results and Analysis}

The dynamic performance of SMIB considering EV has been analyzed with the proposed coordinated (Fuzzy-PID) controller, PSS and PID. The speed deviation $(\Delta \omega)$ and electrical power $\left(P_{e}\right)$ are studied for three cases are considered:

Case 1: in this case, nominal parameters of the system are considered and the system is examined in the absence of EV disturbance as shown in Figure 7 and Figure 8. From figures, it is clear that, the coordinated Fuzzy-PID obtain a robustness performance which given the least value of overshoot than others controllers and it reaches to steady state at small time. 
Case 2: in this case, plug-in electric vehicles as a load disturbance integrated to SMIB. Figure 9 and Figure 10 show the dynamic responses for speed deviation, and electric power for (Fuzzy-PID, PSS, and PID) controllers. From these figures, it notices that the effect of plug-in EVs absorb power and make undershoot in the first cycle. However, the proposed coordinated give a good result under studying of this case

Case 3: in this case, suddenly plug-in electric vehicles as a load disturbance integrated to SMIB from (4:7) sec. Figure 11 show the dynamic responses for speed deviation for (Fuzzy-PID, PSS, and PID) controllers which the effect of plug- in EVs appears at 4 secs and making undershoot. However, the proposed coordinate (Fuzzy-PID) given effectiveness performance and produces smaller overshoot than other. It is cleared that from simulation result as shown in Figure 12, EVs absorb power when plugged into SMIB at 4 secs and the steady state power become $0.8 \mathrm{Pu}$ which the proposed coordinate reach to it throw $1.3 \mathrm{sec}$. (Fuzzy-PID) coordination produce some undershoot than other but it has a good performance.

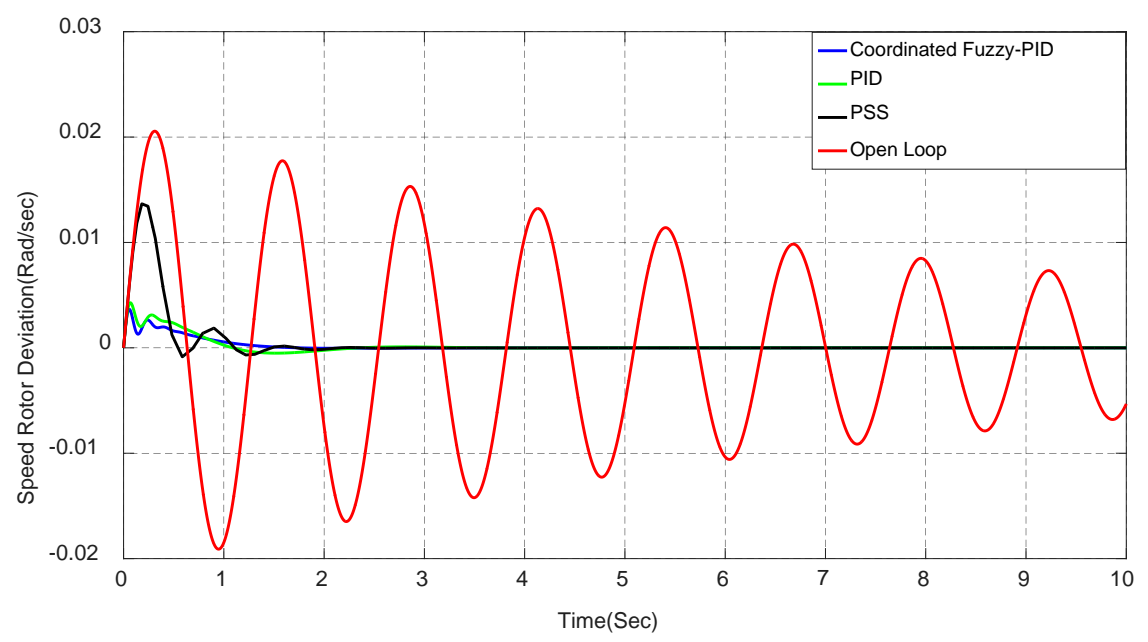

Figure 7. Dynamic responses of speed deviation.

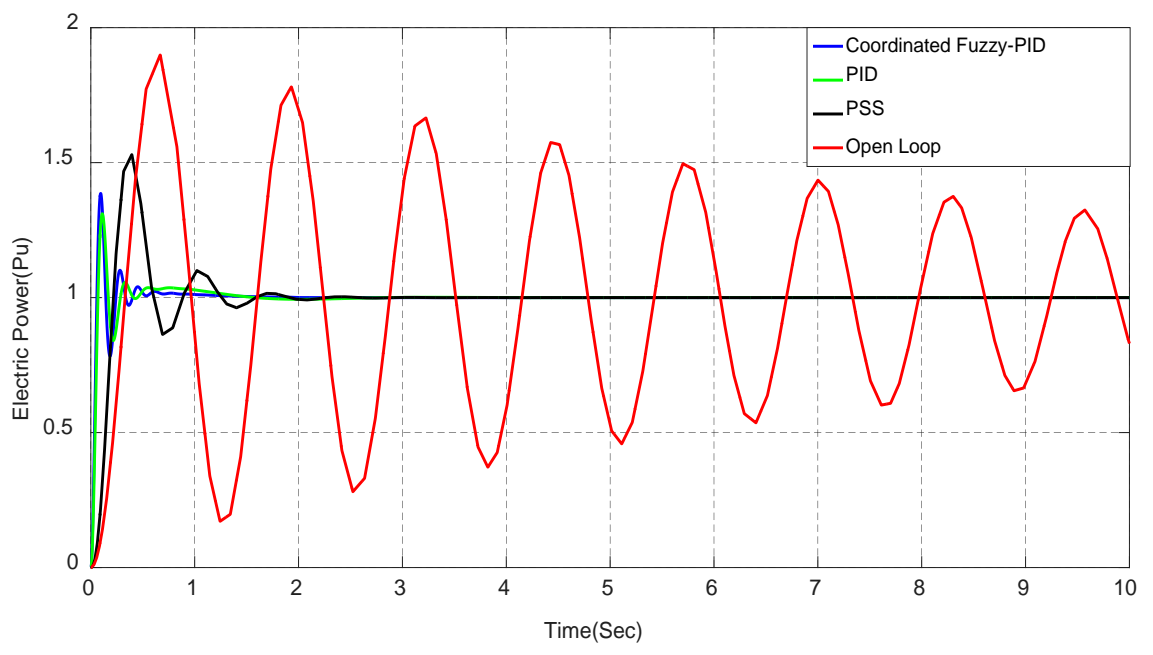

Figure 8. Dynamic responses of electric power. 


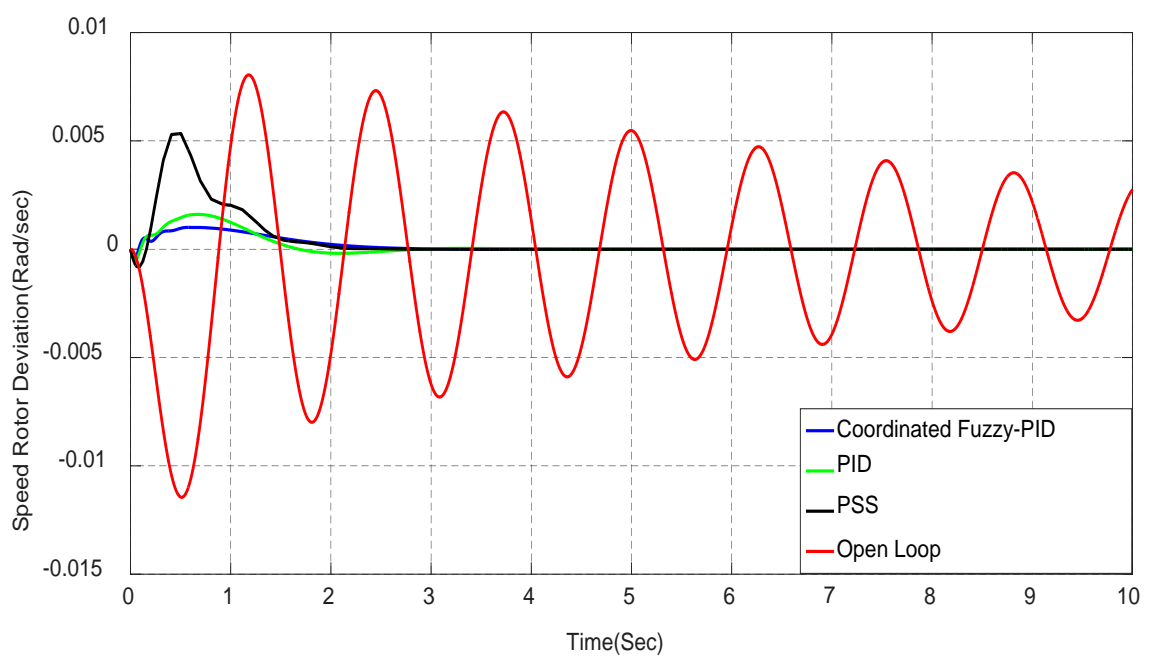

Figure 9. Dynamic responses of speed deviation at plugging EV.

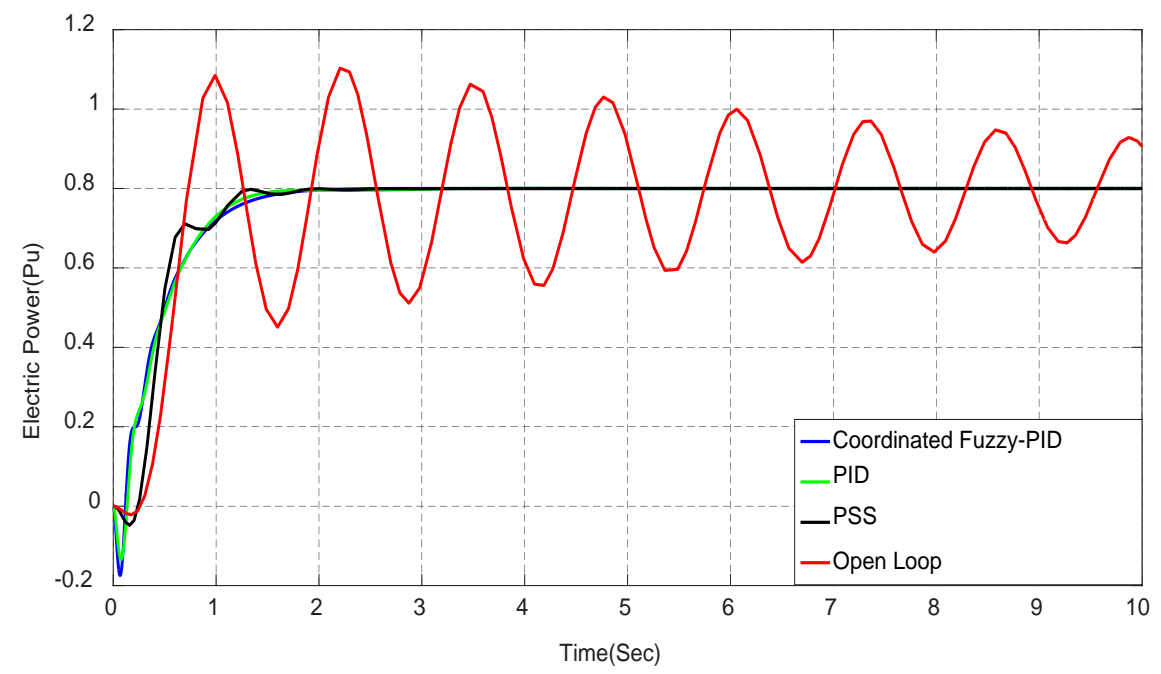

Figure 10. Dynamic responses of electric powerat plugging EV.

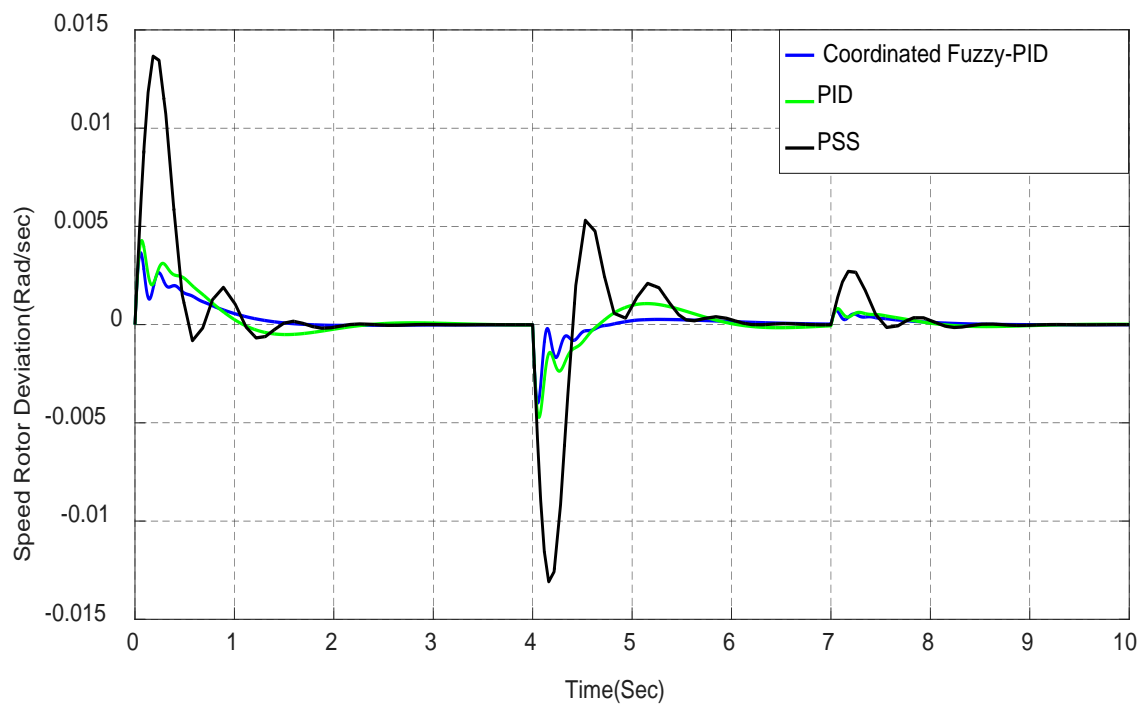

Figure 11. Dynamic responses of speed deviationat plugging EV from (4 - 7) sec. 


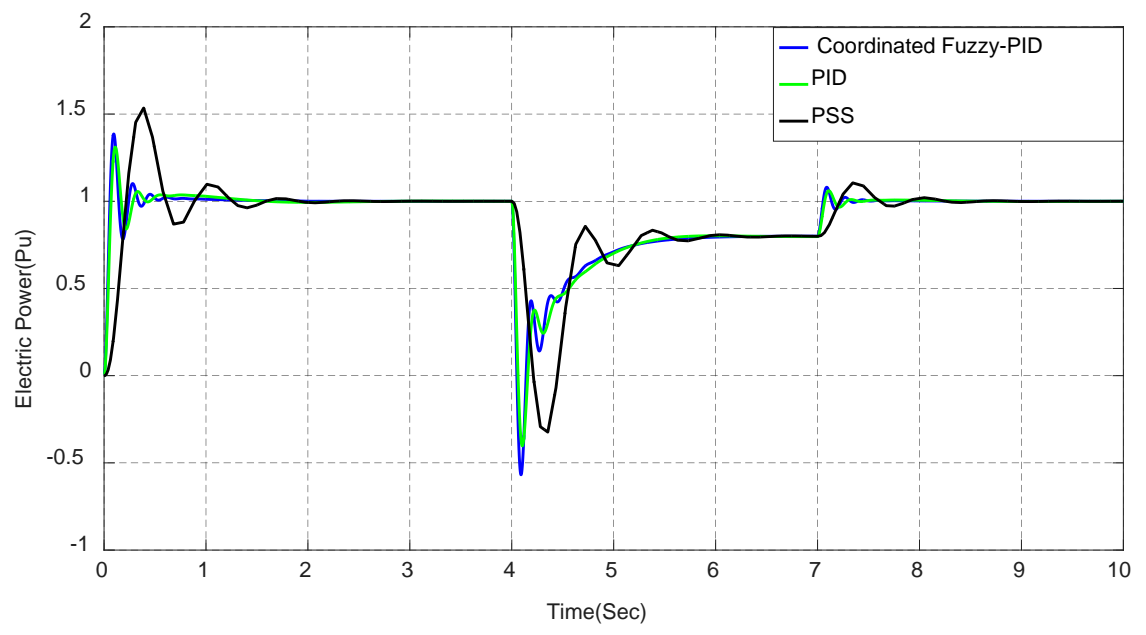

Figure 12. Dynamic responses of electric powerat plugging EV from (4 - 7) sec.

\subsection{Conclusion}

In this study, the coordination (Fuzzy-PID) controller is applied to SMIB power system considering EVs which used as a case study as load disturbance for stability enhancement. A comparison study of the proposed coordinated (Fuzzy-PID) is carried out with conventional controllers such as PID and PSS. The result observed by simulation showed that the coordination (Fuzzy-PID) obtained a robustness performance for all the cases study.

\section{References}

[1] Anderson, P.M. and Fouad, A.A. (1977) Power System Control and Stability. Iowa State University Press, Ames, Iowa, 1.

[2] Saiteja, K. and Krishnarayalu, M. S. (2015) Load Frequency Control of Two-Area Smart Grid. In-ternational Journal of Computer Applications (0975 - 8887), 117. https://doi.org/10.5120/20619-3323

[3] Shimizu, Masuta, Ota, Liyanage, Yokoyama.(2010) System Frequency Controller using Electric Vehicles in Power System with Large Penetration of Renewable energy sources. ICEE2010.

[4] Kundur, P. (1994) Power System Stability and Control. New York: Tata McGrawHill.

[5] Pavan, P., Rbabu, M. and Swathi, S. (2012) Dynamic analysis of Single Machine Infinite Bus System Using Single Input and Dual Input PSS. IEEJ, 3, 632-641.

[6] Larsen, E.V. and Swann, D. A. (1981) Applying Power System Stabilizers, Part I, II, III.IEEE Trans. on Power Apparatus and Systems, 100, 3017-3041. https://doi.org/10.1109/TPAS.1981.316355

[7] Demello, F. P. and Concordia, C. (1969) Concepts of Synchronous Machine Stability as affected by Excitation Control. IEEE Trans. on Power Apparatus System, 189-202.https://doi.org/10.1109/tpas.1969.292452

[8] Hiyama, T. and Nakano, T. (1988) Application of Fuzzy Control Scheme for Stabilization of Electrical Power System. Proceeding of International Workshop on Fuzzy System Applications, 102-103.

[9] Sambariya, D. K., Gupta, R. and Sharma, A. K.(2009) Fuzzy Applications to Single Machine Power System Stabilizers. Journal of Theoretical and Applied Information 
Technology, 5, 317-324.

[10] Shabib, G. (2012) Digital Design of a Power System Stabilizer for Power System Based on Plant-Input Mapping. International Journal of Electrical Power \& Energy Systems (IJEPES), 49, 40-46. https://doi.org/10.1016/j.ijepes.2012.12.010

[11] Shabib, G., Esam, H. and Abd-Elhameed, G. Magdy. (2014) A New Approach to the Digital Implementation of Analog Controllers for a Power System Control. International Journal of Scientific \& Engineering Research (IJSER), 5, 419-427.

[12] Shabib, G., EL Dein, A. Z. and G., Magdy. (2014) Digital Redesign of a PI Controller for a Power System Based on PIM Method. 16th International Middle East Power Systems Conference (MEPCON'14), Ain Shams University, Egypt, December, 23-25, 2014.

[13] Hiyama, T. and Nakano, T. (1988) Application of Fuzzy Control Scheme for Stabilization of Electrical Power System. Proceeding of International Workshop on Fuzzy System Applications, 102-103.

[14] Shabib, G., Esam, H. and Abd-Elhameed, G. Magdy. (2015) Plant Input Mapping Digital Redesign of a PID Controller for a Power System Damping. 3rd International Conference on Energy Systems and Technologies, Cairo, Egypt, February 16-19, 2015.

[15] Swati R., Bhola, J., Manoj, K.P. and Bibhuti, B.R. (2016) Load Frequency Control of a Renewable Hybrid Power System with Simple Fuzzy logic Controller. International Conference on Computing Communication and Automation(ICCCA2016), 918-923

[16] Ali, R., Mohamed, T.H., Qudaih, Y.S. and Mitani. (2013) A new Load Frequency Control Approach in an Isolated Power Systems Using Coefficient Diagram Method. International Journal of Electrical Power \& Energy Systems (IJEPES), 49, 111-116.

[17] Ang, K.H., Chong, G. and Li, Y. (2005) PID Control System Analysis, Design, and Technology. IEEE Trans. on Control Systems Technology, 13.

[18] Astrom, K.J. and Hägglund, T. (1995) PID Controllers: Theory, Design, and Tuning. Research Triangle Park, NC: Instrument Soc. Amer.

[19] G., Magdy. (2016) Digital Redesign of Analog Controllers for Power Systems Using PIM. LAP LAMERT-Academic Publishing, paperback, 164 Pages, 2016.

[20] El-Hawary, M.E. (1998) Electric Power Applications of Fuzzy System. IEEE Press. https://doi.org/10.1109/9780470544457 


\section{Appendix I}

- Generator parameters:

$$
\begin{aligned}
& H=4.63, \text { Damp }=4.4, T_{d o}^{\prime}=7.67, \omega_{B}=377.0, \\
& X_{d}=0.973 p u, \quad X_{d}^{\prime}=0.19 p u, X_{q}=0.55 p u .
\end{aligned}
$$

Exciter parameters:

$$
K_{e}=50.0, T_{e}=0.05
$$

- The K's:

$$
\begin{gathered}
K_{1}=0.5758, K_{2}=0.9738, \quad K_{3}=0.6584, K_{4}=0.5266, K_{5}=-0.0494, \\
K_{6}=0.8450 .
\end{gathered}
$$

- Transmission line:

$$
R_{e}=0.0, X_{e}=0.997 p u .
$$

- Operating point:

$$
Q_{e}=0.015 \mathrm{pu}, V_{\mathrm{t} 0}=1.05 \mathrm{pu}, p_{e}=1.0 \mathrm{pu} .
$$

- Electric Vehicles

- $\mathrm{TEV}=0.1, \mathrm{PEV}=0.2 \mathrm{Pu}$

- PSS Parameter

$\mathrm{K}=50, \mathrm{~T} 1=10, \mathrm{~T} 2=0.25, \mathrm{~T} 3=0.03, \mathrm{~T} 4=0.05, \mathrm{~T} 5=0.15$

\section{Appendix II}

$$
\begin{gathered}
k_{1}=\frac{X_{q}-X_{d}}{\left(X_{e}+X_{d}^{\prime}\right)} I_{q 0} V_{0} \sin \delta_{0}+\frac{E_{q 0} V_{0} \cos \delta_{0}}{\left(X_{e}+X_{q}\right)} \\
K_{2}=\frac{V_{0} \sin \delta_{0}}{\left(X_{e}+X_{d}^{\prime}\right)}, K_{3}=\frac{X_{d}^{\prime}+X_{e}}{\left(X_{d}+X_{e}\right)}, \\
K_{4}=\frac{X_{d}-X_{d}^{\prime}}{\left(X_{e}+X_{d}^{\prime}\right)} V_{0} \sin \delta_{0}, \\
k_{5}=\frac{X_{q}}{\left(X_{e}+X_{q}\right)} \frac{V_{d 0}}{V_{t 0}} V_{0} \cos \delta_{0}+\frac{X_{d}^{\prime}}{\left(X_{e}+X_{d}^{\prime}\right)} \frac{V_{q 0}}{V_{t 0}} V_{0} \sin \delta_{0}, \\
K_{6}=\frac{X_{e}}{\left(X_{e}+X_{d}^{\prime}\right)} \frac{V_{q 0}}{V_{t 0}} .
\end{gathered}
$$


Submit or recommend next manuscript to SCIRP and we will provide best service for you:

Accepting pre-submission inquiries through Email, Facebook, LinkedIn, Twitter, etc. A wide selection of journals (inclusive of 9 subjects, more than 200 journals)

Providing 24-hour high-quality service

User-friendly online submission system

Fair and swift peer-review system

Efficient typesetting and proofreading procedure

Display of the result of downloads and visits, as well as the number of cited articles Maximum dissemination of your research work

Submit your manuscript at: http://papersubmission.scirp.org/

Or contact epe@scirp.org 